Provided for non-commercial research and education use. Not for reproduction, distribution or commercial use.

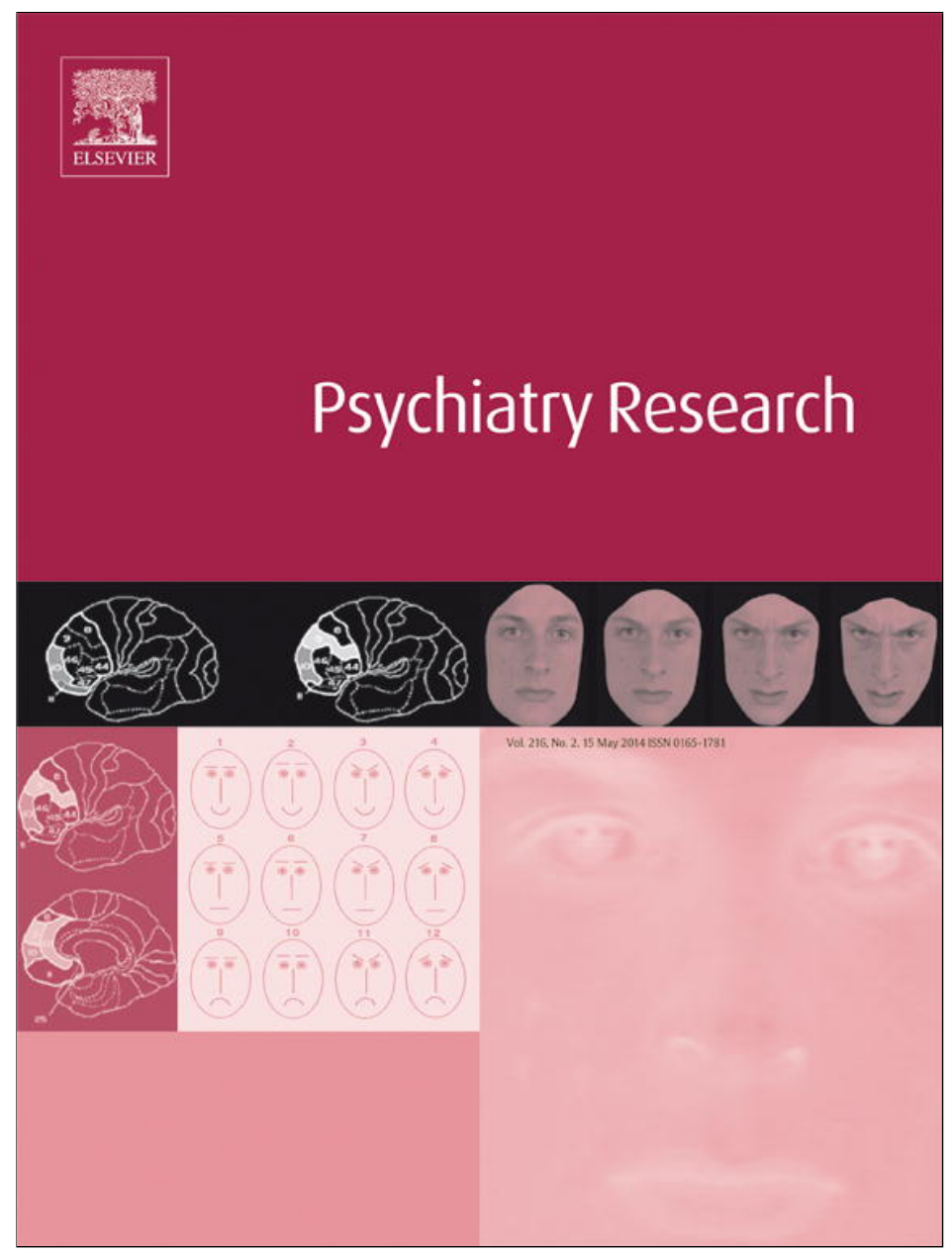

This article appeared in a journal published by Elsevier. The attached copy is furnished to the author for internal non-commercial research and education use, including for instruction at the authors institution and sharing with colleagues.

Other uses, including reproduction and distribution, or selling or licensing copies, or posting to personal, institutional or third party websites are prohibited.

In most cases authors are permitted to post their version of the article (e.g. in Word or Tex form) to their personal website or institutional repository. Authors requiring further information regarding Elsevier's archiving and manuscript policies are encouraged to visit:

http://www.elsevier.com/authorsrights 


\title{
The effect of service satisfaction and spiritual well-being on the quality of life of patients with schizophrenia
}

\author{
Mariangela Lanfredi ${ }^{\text {a }}$, Valentina Candini ${ }^{\text {a }}$, Chiara Buizza ${ }^{\mathrm{a}, \mathrm{f}}$, Clarissa Ferrari ${ }^{\mathrm{a}}$, \\ Maria E. Boero ${ }^{\mathrm{b}}$, Gian M. Giobbio ${ }^{\mathrm{c}, \mathrm{d}}$, Nicoletta Goldschmidt ${ }^{\mathrm{d}}$, Stefania Greppo ${ }^{\mathrm{d}}$, \\ Laura Iozzino a, Paolo Maggi ${ }^{c}$, Anna Melegari ${ }^{b}$, Patrizio Pasqualetti ${ }^{\mathrm{e}}$, Giuseppe Rossi ${ }^{\mathrm{a}}$, \\ Giovanni de Girolamo ${ }^{\mathrm{a}, *}$, the PERDOVE group ${ }^{1}$ \\ a IRCCS San Giovanni di Dio Fatebenefratelli, Brescia, Italy \\ ${ }^{\mathrm{b}}$ Hospital Beata Vergine della Consolata, Torino, Italy \\ ${ }^{\mathrm{c}}$ Hospital Sacro Cuore di Gesù, Milano, Italy \\ ${ }^{\mathrm{d}}$ Hospital Villa Sant'Ambrogio, Milano, Italy \\ ${ }^{\text {e }}$ Medical Statistics E Information Technology, Fatebenefratelli Association for Research, Isola Tiberina, Rome, Italy \\ ${ }^{\mathrm{f}}$ Unit of Clinic and Dynamic Psychology, Department of Clinical and Experimental Sciences, University of Brescia, Brescia, Italy
}

\section{A R T I C L E I N F O}

Article history:

Received 21 June 2013

Received in revised form

15 November 2013

Accepted 28 January 2014

Available online 6 February 2014

Keywords:

Quality of life

Spirituality

Satisfaction

Schizophrenia

Determinants

Residential facilities

\begin{abstract}
A B S T R A C T
Quality of life (QOL) has been considered an important outcome measure in psychiatric research and determinants of QOL have been widely investigated. We aimed at detecting predictors of QOL at baseline and at testing the longitudinal interrelations of the baseline predictors with QOL scores at a 1-year follow-up in a sample of patients living in Residential Facilities (RFs). Logistic regression models were adopted to evaluate the association between WHOQoL-Bref scores and potential determinants of QOL. In addition, all variables significantly associated with QOL domains in the final logistic regression model were included by using the Structural Equation Modeling (SEM). We included 139 patients with a diagnosis of schizophrenia spectrum. In the final logistic regression model level of activity, social support, age, service satisfaction, spiritual well-being and symptoms' severity were identified as predictors of QOL scores at baseline. Longitudinal analyses carried out by SEM showed that 40\% of QOL follow-up variability was explained by QOL at baseline, and significant indirect effects toward QOL at follow-up were found for satisfaction with services and for social support. Rehabilitation plans for people with schizophrenia living in RFs should also consider mediators of change in subjective QOL such as satisfaction with mental health services.
\end{abstract}

(c) 2014 Elsevier Ireland Ltd. All rights reserved.

\section{Introduction}

Although the concept of quality of life (QOL) is of growing interest in schizophrenia research, few studies have investigated predictors of QOL among patients living in Residential Facilities (RFs). In the past years, QOL has become an important outcome measure for those patients, although the associations between predictors and QOL are rather unclear. Several cross-sectional studies have investigated the relationship between the subjective

\footnotetext{
* Corresponding author. Tel.: + 39030350 1590; fax: + 390303533513.

E-mail address: gdegirolamo@fatebenefratelli.it (G. de Girolamo).

${ }^{1}$ The Perdove Group includes the following collaborators: S. Andreose ${ }^{\mathrm{a}}, \mathrm{P}$. Basso $^{a}$, R. Beneduce ${ }^{a}$, F. Bongiorno ${ }^{d}$, V. Braida ${ }^{b}$, E. Cortini ${ }^{c}$, J. Dagani ${ }^{a}$, F. De Dominicis $^{b}$, A. Di Giovannic , A. Ghilardif, A. Jaretti Sodano ${ }^{\mathrm{b}}$, L. Magni ${ }^{\mathrm{a}}$, D. Milazzo ${ }^{\mathrm{e}}$, E. Lo Presti ${ }^{\mathrm{d}}$, L. Paulon ${ }^{\mathrm{e}}$, R. Pioli ${ }^{\mathrm{a}}$, C. Riccid ${ }^{\mathrm{d}}$, L. Rillosi ${ }^{\mathrm{a}}$, G. Savio ${ }^{\mathrm{a}}$, L. Scarattia ${ }^{\mathrm{a}}$ R. Sciolic, L. Veneroni ${ }^{\mathrm{d}}$, S. Zamburlini ${ }^{\mathrm{b}}$, L. Zorzella ${ }^{\mathrm{b}}$.
}

QOL of people with severe mental disorders and socio-demographic and clinical characteristics (Norman et al., 2000; Fitzgerald et al., 2001; Becchi et al., 2004; Caron et al., 2005a, 2005b; Hofer et al., 2006; Narvaez et al., 2008; Hsiao et al., 2012; Fujimaki et al., 2012). In addition, some studies have explored the mediating role of self-related factors, such as lower self-esteem, lack of perceived social support and low self-efficacy in QOL appraisal (Bechdolf et al., 2003; Ritsner et al., 2012).

Nevertheless, little is known about the impact of other subjective variables on self-reported QOL of patients with schizophrenia, especially of those living in RFs (Picardi et al., 2006). Two factors seem particularly worthy of investigation in multi-factorial models: the first is satisfaction with care received (Ruggeri et al., 1994), a multidimensional concept which has been found to be associated with a higher number of unmet needs for care and lower QOL (Ruggeri et al., 2003). The second factor is represented by spiritual and religious well-being: in a recent study the QOL 
spiritual domain of patients with residual schizophrenia explained more than $64 \%$ of the variance of overall QOL score (Shah et al., 2011). Current evidence suggests that positive religious coping is predictive of better psychological domain score of QOL (Nolan et al., 2012) and is related to better treatment outcomes (Rosmarin et al., 2013).

However, the studies aimed at identifying those factors which influence the QOL of patients with schizophrenia did not explain the complex relationship between different set of variables and the QOL. To date, one of the most promising methods to clarify the putative causal determinants of $\mathrm{QOL}$ is the analysis of latent variables (Ruggeri et al., 2001). In particular, the Structural Equation Modeling (SEM) approach has been used in crosssectional studies among patients in chronic stage of schizophrenia (Bechdolf et al., 2003; Hwang et al., 2009).

To the best of our knowledge, no studies have applied the SEM to explore the longitudinal associations between service satisfaction and spiritual and religious well-being in patients with schizophrenia living in RFs. Our primary objective was to determine predictors of QOL at one point in time. Our secondary objective was to test the longitudinal correlations between baseline predictors and QOL scores at 1-year follow-up.

\section{Methods}

\subsection{Participants and procedures}

The current study was conducted within the framework of the PERDOVE study - Epidemiological Project in Residential Facilities on Patients Discharge and Outcomes Evaluation). This is the first prospective study carried out in Italy aimed at collecting comprehensive data about the course and outcomes among a sample of 403 patients living in 23 medium-long term RFs. The study sample included patients with schizophrenia spectrum disorders. A full description of the PERDOVE study sample is given elsewhere (De Girolamo et al., 2013). Inclusion criteria were: a primary psychiatric diagnosis according to DSM-IV-TR and age between 18 and 64 years; exclusion criteria were a primary diagnosis of organic mental disorder and age over 65 years. The study was approved by the local research Ethics Committee and all participants provided written informed consent prior to evaluation.

As a first step, we selected from the PERDOVE sample, patients with a diagnosis of schizophrenia spectrum disorders $(N=272)$. These patients were asked to fill-in the WHOQoL-Bref scale, and 171 accepted. Among these, we selected those participants who completed the QOL assessment at both time points (e.g., baseline and at 1 -year follow-up) obtaining a final sample of 139 patients, that is $51 \%$ of the PERDOVE sample of patients with schizophrenia. Patients who refused to fill in the QOL assessment and those who accepted did not differ in their socio-demographic, clinical and cognitive characteristics.

\subsection{Measures}

\subsubsection{Quality of life}

The Italian version of the WHOQoL-Bref (de Girolamo et al., 2000) was used to estimate the subjective QOL of patients at baseline and follow-up. This instrument includes 26 items on a five-point Likert scale, covering four main domains (physical, psychological, social and environment). Higher scores reflects better QOL

\subsubsection{Psychopathology}

The level of psychopathology was assessed with the Brief Psychiatric Rating Scale [BPRS 4.0; Ventura et al., 1993]; the Health of Nation Outcome Scale [HoNOS12; Wing et al., 1998] was used to assess illness severity. The Personal and Socia Functioning Scale [FPS; Morosini et al., 2000] was used to assess patients' level of overall functioning.

\subsubsection{Cognitive functioning}

Cognitive functioning was assessed with the Repeatable Battery for the Assessment of Neuropsychological Status [RBANS; Ponteri et al., 2007].

\subsubsection{Spirituality and religiousness}

Spiritual and religious well-being was assessed with the Spiritual Well-being scale [SWBS; Paloutzian and Ellison, 1982], which consists of 20 items rated on a seven-point Likert scale providing an overall measure.

\subsubsection{Satisfaction toward care services}

The Verona Service Satisfaction Scale [VSSS-54; Ruggeri et al., 1994], was used to measure satisfaction with mental health services; the items are rated on a sevenpoint Likert scale with global score reflecting higher satisfaction.

\subsubsection{Social support}

The degree of patients' social support was measured asking, to a close informant, the number of close relationships currently entertained by each resident.

\subsubsection{Daily activities}

Level of activities was assessed by two items: type of daily activities (demanding activities or not) and time spent doing nothing per day (h).

\subsection{Statistical analysis}

In order to detect clinically meaningful changes in QOL measures, we dichotomized each subscale score at the median value, in order to classify individuals in lower (below the median) or higher (above the median) subjective QOL. Associations between potential determinants of QOL were assessed with the $\chi^{2}$ test for categorical variables and with $t$-test or Mann-Whitney $U$ test, for continuous variables. The associations of the significant variables were then assessed with logistic linear regression models (stepwise methods for covariate model selection), in which OOL score (high vs. low) was the dependent variable.

We performed SEM with categorical and ordinal variables to test the longitudinal correlations between predictors of QOL at baseline and QOL at follow-up (Bollen, 1996; Hancock and Mueller, 2006). Yule's transformation was adopted to estimate Pearson's correlation coefficients (Kupek, 2006). Missing data were handled by multiple Bayesian imputation. The goodness of fit of the model was checked by several measures: $\chi^{2}$ test, relative $\chi^{2}$ test and comparative fit index (CFI), root mean square error of approximation (RMSEA), Tucker-Lewis coefficient (TLI), and Akaike information criterion (AIC).

Variables were assessed as follows. The latent construct "quality of life" was measured using four subscales of the WHOQoL-Bref. The exogenous variables "satisfaction with services" and "spiritual well-being", measured respectively with the VSSS and the SWBS, were categorized in two classes (below and above the median score values); "symptoms' severity" was measured by BPRS total scores (low vs. moderate); "activity level" and "social support" variables were measured, respectively, by the item "daily time spent doing nothing" (less or more than $3 \mathrm{~h}$ ) and "number of close relationships" ( $\leq 1$ vs. $>1$ ).

All statistical analyses were carried out with SPSS 21.0, SEM was implemented by package AMOS 21.0. Statistical significance was set at $p<0.05$.

\section{Results}

\subsection{Patients' characteristics}

The majority of the patients were male ( $N=89,63.7 \%)$, a total of $85 \%$ of patients were retired or with a disability pension. The mean age was 49 years (S.D. $=9$ ) and they had a long history of illness $($ mean $=24$ years, S.D. $=10)$. The level of psychopathology assessed with the BPRS was moderate (mean=58, S.D.=17); the HONOS mean total score $($ mean $=18.2$, S.D. $=7.8)$ indicated a low symptoms' severity. The levels of cognitive functioning was highly comparable with those of patients with schizophrenia spectrum disorders (mean $=69.5$, S.D. $=9.8$ ), as suggested by RBANS clinical normative data (Iverson et al., 2009).

Patients who had been discharged during the 1-year follow-up were also assessed, with the active collaboration of treating clinicians at Community Mental Health Centres or RFs responsible for the care of these patients. At the 1-year follow-up, 11 patients had been discharged home, 12 transferred to other RFs or supported housing and one was in prison.

\subsection{Associations between $\mathrm{QOL}$ scores at baseline and predictors}

Associations between predictors and baseline QOL domains are shown in Table 1. Among socio-demographic variables, only age (those <40) was significantly associated with higher QOL psychological domain scores. 
Table 1

Socio-demographic and psychosocial characteristics and their associations with QOL domains at baseline.

\begin{tabular}{|c|c|c|c|c|c|c|c|c|c|c|c|c|}
\hline & \multicolumn{3}{|l|}{ Physical } & \multicolumn{3}{|c|}{ Psychological } & \multicolumn{3}{|l|}{ Social } & \multicolumn{3}{|c|}{ Environment } \\
\hline & Low & High & $p^{*}$ & Low & High & $p^{*}$ & Low & High & $p^{*}$ & Low & High & $p^{*}$ \\
\hline \multicolumn{13}{|l|}{ Gender $N(\%)$} \\
\hline Female & 35 (44.9) & $32(36.1)$ & \multirow[t]{2}{*}{ ns } & $32(46.4)$ & $25(36.2)$ & \multirow[t]{2}{*}{ ns } & $28(39.4)$ & $28(42.4)$ & \multirow[t]{2}{*}{ ns } & $22(39.3)$ & $35(42.2)$ & \multirow[t]{2}{*}{ ns } \\
\hline Male & $43(55.1)$ & 39 (63.9) & & $37(53.6)$ & $44(63.8)$ & & $43(60.6)$ & $38(57.6)$ & & $34(60.7)$ & $48(57.8)$ & \\
\hline \multicolumn{13}{|l|}{ Age $N(\%)$} \\
\hline$<40$ & $14(17.9)$ & $13(21.3)$ & \multirow[t]{2}{*}{ ns } & $7(10.1)$ & $20(29.0)$ & \multirow[t]{2}{*}{0.005} & $12(16.9)$ & $15(22.7)$ & \multirow[t]{2}{*}{ ns } & $8(14.3)$ & 19 (22.9) & \multirow[t]{2}{*}{ ns } \\
\hline$>40$ & $64(82.1)$ & 48 (78.7) & & $62(89.9)$ & $49(71.0)$ & & $59(83.1)$ & $51(77.3)$ & & $48(85.7)$ & $64(77.1)$ & \\
\hline \multicolumn{13}{|l|}{ Marital status N (\%) } \\
\hline Married/cohabiting & $16(20.5)$ & $11(18.0)$ & \multirow[t]{2}{*}{ ns } & $16(23.2)$ & $11(15.9)$ & \multirow[t]{2}{*}{ ns } & $12(16.9)$ & $15(22.7)$ & \multirow[t]{2}{*}{ ns } & $15(26.8)$ & $12(14.5)$ & \multirow[t]{2}{*}{ ns } \\
\hline Single/widowed/divorced & $62(79.5)$ & $50(82.0)$ & & $53(76.8)$ & $58(84.1)$ & & $59(83.1)$ & $51(77.3)$ & & $41(73.2)$ & $71(85.5)$ & \\
\hline \multicolumn{13}{|l|}{ Education $N(\%)$} \\
\hline$<8$ years & $46(59.0)$ & $40(65.6)$ & \multirow[t]{2}{*}{ ns } & $40(58.0)$ & $45(65.2)$ & \multirow[t]{2}{*}{ ns } & $40(56.3)$ & $45(68.2)$ & \multirow[t]{2}{*}{ ns } & $35(62.5)$ & $51(61.4)$ & \multirow[t]{2}{*}{ ns } \\
\hline$>8$ years & $32(41.0)$ & $21(34.4)$ & & $29(42.0)$ & $24(34.8)$ & & $31(43.7)$ & $21(31.8)$ & & $21(37.5)$ & $32(38.6)$ & \\
\hline \multicolumn{13}{|l|}{ Employment status $N(\%)$} \\
\hline Retired/disabled & $66(84.6)$ & $49(80.3)$ & \multirow[t]{2}{*}{ ns } & $58(84.1)$ & $56(81.2)$ & \multirow[t]{2}{*}{ ns } & $58(81.7)$ & $55(83.3)$ & \multirow[t]{2}{*}{ ns } & $46(82.1)$ & $69(83.1)$ & $\mathrm{ns}$ \\
\hline Other (housewife, student, etc.) & $12(15.4)$ & $12(19.7)$ & & $11(15.9)$ & $13(18.8)$ & & $13(18.3)$ & $11(16.7)$ & & $10(17.9)$ & $14(16.9)$ & \\
\hline Illness duration (years) & $24.2(10.8)$ & 23.2 & ns & $24.2(10.9)$ & 23.2 & ns & 23 & 24.4 & ns & 24.9 & 22.9 & $\mathrm{~ns}$ \\
\hline Mean (S.D.) & & $(9.8)$ & & & $(9.8)$ & & $(11.3)$ & $(9.4)$ & & $(11.7)$ & $(9.3)$ & \\
\hline Age at 1 st contact with CMHS & 25.7 & 26.4 & ns & 28.1 & 23.9 & $0.014^{\S}$ & 27.8 & 24.2 & $0.033^{\S}$ & 27.8 & 24.8 & $\mathrm{~ns}$ \\
\hline Mean (S.D.) & $(9.9)$ & $(9.6)$ & & $(10.2)$ & $(8.9)$ & & $(10.7)$ & $(8.5)$ & & $(10.8)$ & $(8.9)$ & \\
\hline Time spent doing nothing $N(\%)$ & & & & & & & & & & & & \\
\hline More than 3 h/day & $21(27.3)$ & $27(44.3)$ & 0.037 & $16(23.2)$ & $32(47.0)$ & 0.003 & $18(25.4)$ & $25(44.6)$ & 0.018 & $15(26.8)$ & $33(40.2)$ & $\mathrm{ns}$ \\
\hline Less than $3 \mathrm{~h} /$ day & $56(72.7)$ & $34(55.7)$ & & $53(76.8)$ & $36(53.0)$ & & $53(74.6)$ & $36(55.4)$ & & $41(73.2)$ & $49(59.8)$ & \\
\hline Type of daily activities $N(\%)$ & & & & & & & & & & & & \\
\hline Demanding activities & $64(82.1)$ & 39 (63.9) & 0.016 & $53(76.8)$ & $49(71.0)$ & ns & $56(78.9)$ & $45(68.2)$ & ns & $43(76.8)$ & $60(72.3)$ & $\mathrm{ns}$ \\
\hline Not demanding activities & $14(17.9)$ & $22(36.1)$ & & $16(23.2)$ & $20(29.0)$ & & $15(21.1)$ & $21(31.8)$ & & $13(23.2)$ & $23(27.7)$ & \\
\hline Close relationship $N(\%)$ & & & & & & & & & & & & \\
\hline$<1$ & $28(41.2)$ & $17(32.7)$ & ns & $24(40.7)$ & $21(35.0)$ & ns & $28(50.0)$ & $17(27.4)$ & 0.012 & $18(40.0)$ & $27(36.0)$ & $\mathrm{ns}$ \\
\hline$>1$ & $40(58.8)$ & $35(67.3)$ & & $35(59.3)$ & $39(65.0)$ & & $28(50.0)$ & $45(72.6)$ & & $27(60.0)$ & $48(64.0)$ & \\
\hline
\end{tabular}

$* \chi^{2}$ or $t$-test.

$\S p$-Value (significance $p<0.05$ ).

With regard to social contacts, we found that a higher number of close relationships was positively associated with QOL social domain higher scores. Moreover, in regard to living conditions in RFs, more time spent doing nothing was negatively associated with physical, psychological and social domain scores of QOL; on the contrary, the number of daily life activities was only associated with lower physical domain scores.

With regard to clinical variables, an earlier age at first contact with Community Mental Health Services (CMHS) was inversely associated with QOL psychological and social domain scores. No associations were found for RBANS scores, FPS scores and QOL levels. Instead, a low severity of psychopathology and a low psychosocial functioning were associated to higher scores on the QOL psychological and environment domains. In addition, moderate-high satisfaction with spiritual and religious well-being was positively associated with three different domains of QOL. Lastly, a higher level of service satisfaction, as assessed by the VSSS, was positively associated with higher scores in all QOL domains.

\subsection{Predictors of $\mathrm{QOL}$ at baseline using multiple logistic regression analyses}

We included those factors which were associated with QOL into five different multiple logistic regression models for each of the four domains, in order to identify QOL predictors at baseline (Table 2).

The first model tested psychosocial variables: time spent doing nothing, type of daily activities and close relationships; the second model included objective variables: age and age at first contact with CMHS. Higher psychological QOL was 3.7 times and 2.9 times more likely among young patients and among those who spent less than $3 \mathrm{~h}$ per day doing nothing, respectively. Relevant predictors of higher QOL in the social domain were, instead, the level of daily activities and the number of close relationships.

Similarly, a third multiple logistic regression model was carried out for the subjective variables "service satisfaction" and "spiritual well-being". VSSS scores were associated with all domains, except the psychological domain, whereas spiritual and religious higher scores were positively associated with psychological and environment domain scores.

Clinical variables, were analyzed through the fourth logistic model: only lower BPRS scores were associated with higher QOL scores in the psychological and environment domains (Table 3).

Finally, a fifth model was computed including all the above variables significantly related to each QOL domain. Patients with a younger age and those being more active remained associated with higher scores in the psychological domain; those having a higher number of social contacts were related to higher social domain scores. Services satisfaction and spiritual well-being variables were confirmed as relevant QOL predictors; in particular the former showed the highest estimated odds ratios in the social and environment domains.

\subsection{Structural Equation Model for longitudinal outcomes}

All variables significantly associated to the four QOL domains in the final logistic regression model were included in SEM. In addition, we also included the BPRS scale, in order to investigate 
Table 2

Clinical and subjective characteristics and their associations with QOL domains at baseline.

\begin{tabular}{|c|c|c|c|c|c|c|c|c|c|c|c|c|}
\hline & \multicolumn{3}{|l|}{ Physical } & \multicolumn{3}{|c|}{ Psychological } & \multicolumn{3}{|l|}{ Social } & \multicolumn{3}{|c|}{ Environment } \\
\hline & Low & High & $p^{*}$ & Low & High & $p^{*}$ & Low & High & $p^{*}$ & Low & High & $p^{*}$ \\
\hline \multicolumn{13}{|l|}{ BPRS N (\%) } \\
\hline Low $(<72)$ & $63(80.8)$ & $46(75.4)$ & \multirow[b]{2}{*}{ ns } & $48(69.6)$ & $60(87.0)$ & \multirow[b]{2}{*}{0.013} & $52(73.3)$ & $55(83.3)$ & \multirow[b]{2}{*}{ ns } & $38(67.9)$ & 71 (85.5) & \multirow[b]{2}{*}{0.013} \\
\hline Moderate $(>72)$ & $15(19.2)$ & $15(24.6)$ & & $21(30.4)$ & $9(13.0)$ & & 19 (26.7) & $11(16.7)$ & & $18(32.1)$ & $12(14.5)$ & \\
\hline \multicolumn{13}{|l|}{ FPS $N(\%)$} \\
\hline Severe $(<40)$ & $47(60.3)$ & $28(45.9)$ & \multirow[b]{2}{*}{ ns } & $43(62.3)$ & $32(46.4)$ & \multirow[b]{2}{*}{ ns } & $42(59.2)$ & $33(50.0)$ & \multirow[b]{2}{*}{ ns } & $32(57.1)$ & $43(51.8)$ & \multirow[b]{2}{*}{ ns } \\
\hline Moderate $(>40)$ & $31(39.7)$ & $33(54.1)$ & & $26(37.7)$ & 37 (53.6) & & $29(40.8)$ & $33(50.0)$ & & $24(42.9)$ & $40(48.2)$ & \\
\hline \multicolumn{13}{|l|}{ HONOS N (\%) } \\
\hline Low $(<12)$ & $21(27.3)$ & $19(31.7)$ & \multirow{3}{*}{ ns } & $14(20.3)$ & $25(37.3)$ & \multirow{3}{*}{0.025} & $18(25.4)$ & $21(19.6)$ & \multirow{3}{*}{ ns } & $11(19.6)$ & $29(35.8)$ & \multirow{3}{*}{0.048} \\
\hline Moderate (13-24) & 46 (59.7) & $27(45)$ & & $38(55.1)$ & $35(52.2)$ & & 41 (57.7) & $31(55.4)$ & & $31(55.4)$ & $42(51.9)$ & \\
\hline $\operatorname{High}(>25)$ & $10(13.0)$ & $14(23.3)$ & & $17(24.6)$ & 7 (10.5) & & $12(16.9)$ & $12(18.8)$ & & $14(25.0)$ & $10(12.3)$ & \\
\hline \multicolumn{13}{|l|}{ RBANS N (\%) } \\
\hline Low $(<69)$ & $30(44.8)$ & $32(56.1)$ & \multirow{3}{*}{ ns } & $33(55.0)$ & $29(46.0)$ & \multirow{3}{*}{ ns } & $32(50.8)$ & $29(49.1)$ & \multirow{3}{*}{ ns } & $23(46.0)$ & $39(52.7)$ & \multirow{3}{*}{ ns } \\
\hline Moderate (70-79) & $34(50.7)$ & $23(40.4)$ & & $26(43.3)$ & $30(47.6)$ & & $28(44.4)$ & $28(47.5)$ & & $25(50.0)$ & $32(43.2)$ & \\
\hline $\operatorname{High}(>80)$ & $3(4.5)$ & $2(3.5)$ & & $1(1.7)$ & $4(6.3)$ & & $3(4.8)$ & $2(3.4)$ & & $2(4.0)$ & $3(4.1)$ & \\
\hline \multicolumn{13}{|c|}{ SWBS $(\mathrm{Me}=76), N(\%)$} \\
\hline Low-moderate & $43(57.3)$ & $22(37.3)$ & \multirow[b]{2}{*}{0.021} & $41(62.1)$ & $24(35.3)$ & \multirow[b]{2}{*}{0.002} & $39(55.7)$ & $26(41.3)$ & \multirow[b]{2}{*}{ ns } & $35(67.3)$ & $30(36.6)$ & \multirow{2}{*}{0.001} \\
\hline Moderate-high & $32(42.7)$ & $37(62.7)$ & & $25(37.9)$ & $44(64.7)$ & & $31(44.3)$ & $37(58.7)$ & & $17(32.7)$ & $52(63.4)$ & \\
\hline \multicolumn{13}{|l|}{ VSSS $(\mathrm{Me}=3.5), N(\%)$} \\
\hline Dissatisfied & $30(41.7)$ & $12(20.3)$ & \multirow{2}{*}{0.009} & $25(39.7)$ & $16(23.9)$ & \multirow{2}{*}{0.05} & $31(44.3)$ & 10 (16.9) & & $28(57.1)$ & $14(17.1)$ & \\
\hline Satisfied & $42(58.3)$ & $47(79.7)$ & & $38(60.3)$ & $51(76.1)$ & & $39(55.7)$ & $49(83.1)$ & 0.001 & $21(42.9)$ & 68 (82.9) & $<0.001$ \\
\hline
\end{tabular}

Note: $\mathrm{Me}=$ median value, BPRS=Brief Psychiatric Rating Scale, FPS=Personal and Social Functioning Scale, HONOS=Health of Nation Outcome Scale, RBANS=Repeatable Battery for the Assessment of Neuropsychological Status, SWBS=Spiritual Well-being scale, and VSSS=Verona Service Satisfaction Scale.

$* \chi^{2}$ and $p$-value (significance $p<0.05$ ).

Table 3

Summary of logistic regression analyses examining the relationship between predictors and high QOL at baseline.

\begin{tabular}{|c|c|c|c|c|c|c|c|c|}
\hline & \multicolumn{2}{|c|}{ Physical } & \multicolumn{2}{|c|}{ Psychological } & \multicolumn{2}{|c|}{ Social } & \multicolumn{2}{|c|}{ Environment } \\
\hline & OR & $(95 \% \mathrm{CI})$ & OR & $(95 \% \mathrm{CI})$ & OR & $(95 \% \mathrm{CI})$ & OR & $(95 \% \mathrm{CI})$ \\
\hline \multicolumn{9}{|l|}{ 1st Model (psychosocial variables) } \\
\hline Time spent doing nothing $(<3 \mathrm{~h} />3 \mathrm{~h})$ & - & - & 2.90 & $1.41-6.13$ & 2.50 & $1.12-5.72$ & & \\
\hline Type of daily activities (demanding vs. not) & 2.50 & $1.16-5.54$ & & & - & - & & \\
\hline Close relationship ( $<1$ vs. $>1)$ & & & & & 2.80 & $1.29-6.46$ & & \\
\hline \multicolumn{9}{|l|}{ 2nd Model (objective indicators) } \\
\hline Age (younger vs. older) & & & 3.70 & $1.41-9.29$ & - & - & & \\
\hline Age at first contact with CMHS & & & - & - & 0.96 & $0.93-0.99$ & & \\
\hline \multicolumn{9}{|c|}{ 3rd Model (satisfaction with services and spirituality at baseline) } \\
\hline VSSS (high vs. low) & 3.02 & $1.30-6.97$ & - & - & 4.55 & $1.87-11.07$ & 5.25 & $2.18-12.63$ \\
\hline SWBS (high vs. low) & & & 3.00 & $1.45-6.21$ & - & - & 2.50 & $1.07-5.64$ \\
\hline \multicolumn{9}{|c|}{ 4th Model (psychopathology and psychosocial functioning at baseline) } \\
\hline BPRS (low vs. moderate) & & & 3.20 & $1.30-7.92$ & & & 3.01 & $1.29-7.03$ \\
\hline HONOS (low vs. moderate vs. high) & & & - & - & & & - & - \\
\hline \multicolumn{9}{|c|}{ 5th Model (objective, psychosocial, satisfaction and spirituality variables, psychopathology and psychosocial functioning) } \\
\hline Age at first contact with CMHS & - & - & - & - & - & - & - & - \\
\hline Close relationship ( $<1$ vs. $>1$ ) & - & - & - & - & 3.10 & $1.26-7.62$ & - & - \\
\hline Time spent doing nothing $(<3 \mathrm{~h} />3 \mathrm{~h})$ & - & - & 2.40 & $1.09-5.25$ & - & - & - & - \\
\hline Age (younger vs. older) & - & - & 3.70 & $1.36-9.86$ & - & - & - & - \\
\hline BPRS (low vs. moderate) & - & - & - & - & - & - & - & - \\
\hline VSSS (high vs. low) & 2.70 & $1.21-6.20$ & - & - & 6.00 & $2.25-16.13$ & 5.25 & $2.18-12.63$ \\
\hline SWBS (high vs. low) & - & - & 2.70 & $1.30-5.77$ & - & - & 2.50 & $1.07-5.64$ \\
\hline
\end{tabular}

Note: $\mathrm{OR}=$ odds ratio, $\mathrm{BPRS}=$ Brief Psychiatric Rating Scale, HONOS=Health of Nation Outcome Scale, VSSS=Verona Service Satisfaction Scale, and SWBS $=$ Spiritual Wellbeing scale.

the effect of the level of psychopathology on QOL. The theoretical model is displayed in Fig. 1, in which QOL at follow-up was considered as an endogenous variable and the relationship between exogenous variables and QOL at baseline and at followup were tested.

BPRS variable and relationships from exogenous variables toward QOL at follow-up were removed from the model because they were not statistically significant. Model fit indices of the final model showed a notable goodness of fit: $\chi^{2}=67.51$, d.f. $=46$, $p=0.184$, relative $\chi^{2}=1.16$ (less than 2.5 indicate a good fit), $\mathrm{CFI}=0.97$ ( $97 \%$ of covariation in data was reproduced by the final model), TLI=0.96 (higher than 0.9 indicate a good fit), RSMEA $=0.034$ (CI 0.00-0.065), and $\mathrm{AIC}=159.5$ (lower than $\mathrm{AIC}=206.1$ of the theoretical model).

The predictors of logistic regression were confirmed also for the latent construct $\mathrm{QOL}$ at baseline. In particular, transforming the 


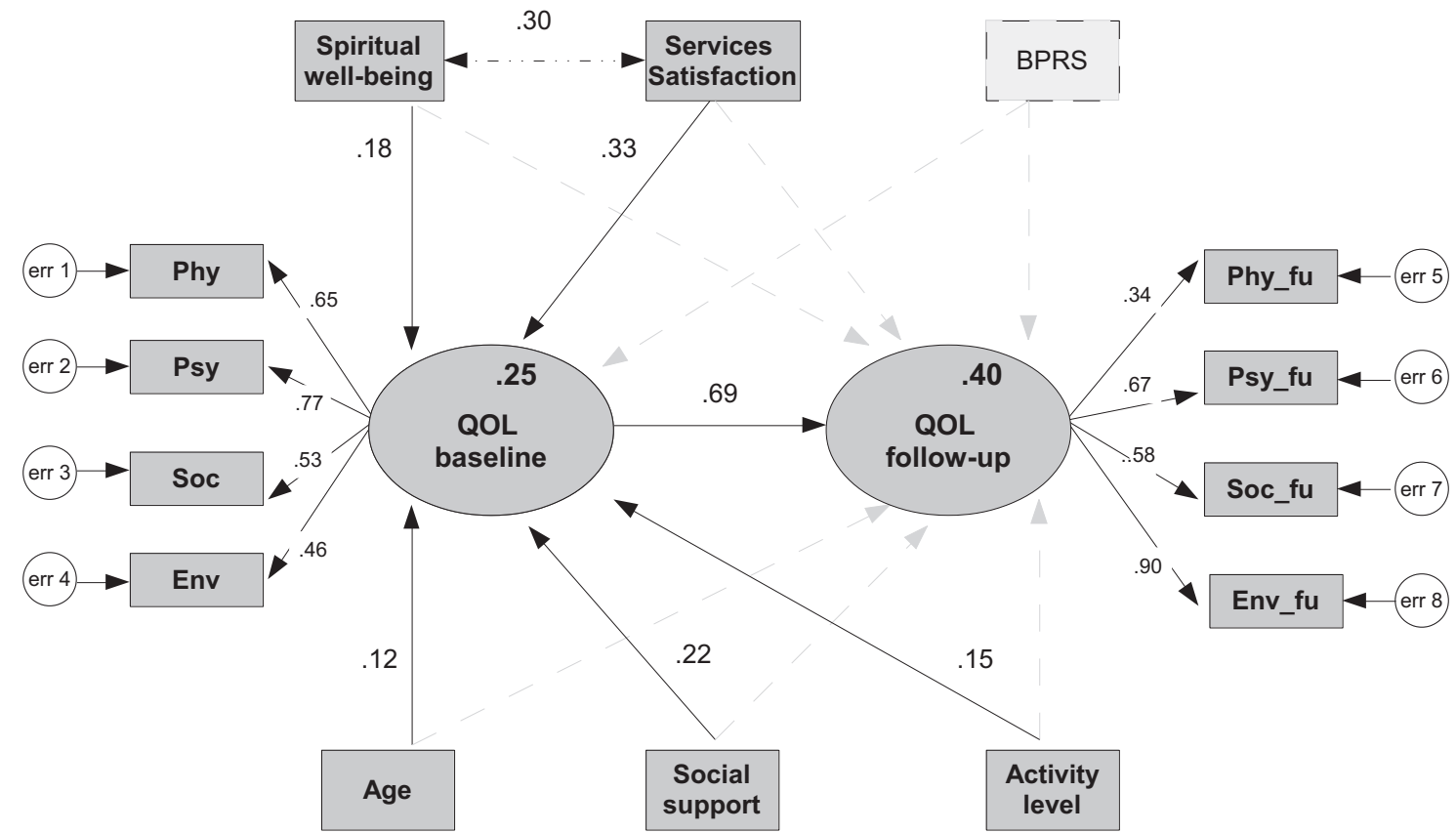

Fig. 1. Structural Equation Model for longitudinal analysis of QOL: standardized estimates. All regression coefficients and factor loadings are significant at $p<0.005$. In light gray non-significant variables and relationship (dashed light gray) are reported. In black dotted line the correlation (standardized covariance) parameter between spiritual well-being and services satisfaction is depicted. The number of different parameters to be estimated was 46 , including covariance parameters between exogenous variables for improving the model fit.

regression coefficients in terms of odds ratio (Kupek, 2006), we identified service satisfaction and social support as effective predictors of QOL at baseline with $\mathrm{OR}=1.67(1.20-2.39)$ and $\mathrm{OR}=1.35$ (1.03-1.78), respectively. Weak relationships were observed for other exogenous variables, including spiritual wellbeing $(\mathrm{OR}=1.22,95 \% \mathrm{CI}[1.01-1.50])$, activity level $(\mathrm{OR}=1.30,95 \% \mathrm{CI}$ [1.02-1.66]) and age $(\mathrm{OR}=1.22,95 \% \mathrm{CI}[1.01-1.42])$. Moreover, a mutual correlation $(r=0.30, p<0.001)$ was found between service satisfaction and spiritual well-being. All predictors contributed to explain the $25 \%$ variability of QOL at baseline. Although none of the QOL predictors at baseline had a significant direct relationship with QOL at follow-up, the analysis of indirect effects (Table 4) of predictors on latent constructs, pointed at a relationship between predictors and QOL also at 1-year follow-up. In particular, through the very high correlation between $\mathrm{QOL}$ at baseline and $\mathrm{QOL}$ at follow-up (with $r=0.69, p<0.002$, and $40 \%$ of QOL follow-up variability explained by QOL at baseline), service satisfaction and social support were related to the latent QOL at follow-up with $r=0.23(p<0.001)$ and $r=0.15(p<0.05)$, respectively.

Finally, comparing the factor loading estimates of QOL indicators at baseline and at follow-up, we noted that the main contributions to QOL at baseline were given by the social and the environment domains, with factor loading equal to 0.77 and 0.65 , respectively; on the other hand, for QOL at follow-up, we found the environment and psychological domains to be the two most important indicators, loading equal to 0.90 and 0.67 , respectively.

\section{Discussion}

This study aimed at estimating the key determinants of QOL at baseline and at 1-year follow-up in a sample of patients with schizophrenia living in RFs by using SEM.

In line with previous research (Ruggeri et al., 1995, 2001), we found that service satisfaction was important for the perceived QOL at baseline by using logistic models. At baseline, service satisfaction was strongly associated to high scores on all QOL different domains in this clinical population. Using SEM, we found that patients with higher service satisfaction were $67 \%$ more likely to report higher QOL, and this predictor explained $18 \%$ of the total QOL variance: this result is in line with a previous study (Ruggeri et al., 2002) that found that this variable explained $22 \%$ of QOL variance. The clinical implication of this finding for the care delivered in residential settings is straightforward: care takers should make every effort in order to improve satisfaction toward services; since patients' stay in RFs is generally prolonged, carers should pay great attention to individual needs and preferences, should work to realize a domestic-like environment (as opposed to an institutional, dehumanizing environment), and should develop individual treatment plans, all conditions favoring service satisfaction and, through that, a subjective QOL.

\subsection{Social support and activity level}

With regard to social support, our findings are equally in agreement with previous data indicating a direct association between a larger social network and QOL of severely ill patients (Caron et al., 1998; Ruggeri et al., 2002). This result has clear implications for the appropriate management of patients living in assisted settings: care takers should promote effective interventions to foster patients' supportive social relationships.

As Kelly et al. (2001), we found that level of activities was weakly associated with QOL at baseline. A possible reason for such feeble association might be the lack of a qualitative assessment. In fact, previous studies on QOL of outpatients with psychosis reported that satisfaction with daily activities was associated with improvement in QOL (Bengtsson-Tops and Hansson, 2001; Eklund and Backstrom, 2005; Picardi et al., 2006).

\subsection{Religiousness and spiritual well-being}

Moreover, a weak relationship was found between "spiritual and religious well-being" and QOL at baseline. Nonetheless, higher 
Table 4

Standardized SEM direct, indirect and total effects on QOL at baseline and at follow-up.

\begin{tabular}{|c|c|c|c|c|c|c|c|}
\hline & & Age & Activity level & Social support & Service satisfaction & Spiritual well-being & QOL baseline \\
\hline \multirow[t]{6}{*}{ Direct } & QOL baseline & 0.121 & 0.182 & 0.217 & 0.329 & 0.149 & 0.000 \\
\hline & QOL follow-up & 0.000 & 0.000 & 0.000 & 0.000 & 0.000 & 0.694 \\
\hline & Phy domain & 0.000 & 0.000 & 0.000 & 0.000 & 0.000 & 0.462 \\
\hline & Psy domain & 0.000 & 0.000 & 0.000 & 0.000 & 0.000 & 0.532 \\
\hline & Soc domain & 0.000 & 0.000 & 0.000 & 0.000 & 0.000 & 0.766 \\
\hline & Env domain & 0.000 & 0.000 & 0.000 & 0.000 & 0.000 & 0.646 \\
\hline \multirow[t]{6}{*}{ Indirect } & QOL baseline & 0.000 & 0.000 & 0.000 & 0.000 & 0.000 & 0.000 \\
\hline & QOL FU & 0.084 & 0.126 & 0.151 & 0.228 & 0.103 & 0.000 \\
\hline & Phy domain FU & 0.029 & 0.044 & 0.052 & 0.079 & 0.036 & 0.239 \\
\hline & Psy domain FU & 0.056 & 0.084 & 0.1 & 0.152 & 0.069 & 0.462 \\
\hline & Soc domain FU & 0.049 & 0.074 & 0.088 & 0.133 & 0.06 & 0.405 \\
\hline & Env domain FU & 0.075 & 0.113 & 0.135 & 0.204 & 0.092 & 0.622 \\
\hline \multirow[t]{2}{*}{ Total } & QOL baseline & 0.121 & 0.182 & 0.217 & 0.329 & 0.149 & 0.000 \\
\hline & QOL follow-up & 0.084 & 0.126 & 0.151 & 0.228 & 0.103 & 0.694 \\
\hline
\end{tabular}

spiritual well-being indirectly affected QOL at baseline through an enhancement of service satisfaction, since SWBS and VSSS variables were found mutually correlated. A recent study (Mohr et al., 2011) found that higher proficiency of religion in giving meaning to life was positively associated to improved QOL in psychotic disorders. The weakness of the relationship between spirituality and QOL in our study might be due to the lack of efficient mediation variables on QOL, such as sense of personal effectiveness and sense of optimism (Ho et al., 2010). In fact, a number of studies seems to suggest that a large proportion of subjective QOL is associated to self-related constructs, such as perceived autonomy (Zissi et al., 1998) and self-efficacy (Bechdolf et al., 2003).

\subsection{QOL and psychopathology}

We did not find that psychopathology had a significant impact on QOL. The impact of psychopathology on QOL has been controversial and a recent meta-analysis (Eack and Newhill, 2007) reported that QOL was only modestly related to symptoms of mental illness.

The lack of a significant association between BPRS and QOL scores in our study is consistent with the previous study (Wilsond'Almeida et al., 2013) showing that symptoms improvement was not correlated with QOL enhancement.

\subsection{Longitudinal findings}

From a longitudinal perspective, variables associated to better QOL at baseline did not directly influence QOL at 1-year follow-up. Nevertheless, we found indirect effects of service satisfaction and social support on QOL at follow-up, mediated by baseline QOL. It is possible that predictors change their relevance between points of evaluation or that our model did not include other consistent predictors of QOL. Our main longitudinal finding is that QOL at baseline accounted for $40 \%$ of variance in the same factor at follow-up. This is consistent with other longitudinal studies done in different clinical samples (Slade et al., 2004; Hansson and Bjorkman, 2007). Moreover, Landolt et al. (2012), using a SEM approach in a groups of patients with a first-episode of schizophrenia, found that fewer unmet needs, higher depression, baseline QOL, age and gender (female) were all factors associated with higher QOL at follow-up. In our study, besides service satisfaction and social support, the other predictors of change were longitudinally inconsistent. A tentative explanation of our findings is that patients with enhanced QOL also are those more satisfied with care, who have more social contacts and who report better spiritual well-being: interesting enough, all these variables are modifiable, and therefore open the way for significant improvement in health care delivery.

Another longitudinal finding is related to the change of factor loadings of the two latent QOL constructs. The main implication of the prominent contribution of the environment domain to QOL at follow-up is that greater attention should be directed to environmental features of residential settings.

This study should be interpreted with caution due to certain methodological limitations. Sample size was rather limited, and this prevented us from undertaking a deeper analysis of the SWBS and VSSS subscales in doing the SEM analyses. Moreover, although the social support is a multi-dimensional construct, in our study it was measured by one single quantitative question. In addition, in our study the link between baseline QOL and QOL at follow-up included values which remained rather stable over 1-year followup. Low improvements may be related to difficulties in assessing illness course and major changes in symptomatology in people with a long history of illness.

In conclusion, this study showed that subjective estimates (as service satisfaction) and psychosocial predictors (as social relationships) should be considered to address interventions able to achieve more favorable long-term benefits through QOL enhancement. Rehabilitative interventions should optimize the potential determinants of QOL by interventions tailored to patients longterm needs (Ruggeri et al., 2003) and the quality of services, and aimed at enhancing the perceived social support of people with schizophrenia living in RFs. Moreover, this study showed that higher spiritual well-being might indirectly affect QOL at baseline through an impact on service satisfaction. For this reason, recovery-oriented interventions (Silverstein and Bellack, 2008) delivered in RFs should include the assessment of cultural factors, such as religion and spirituality, that have been found easy to incorporate in usual clinical settings (Huguelet et al., 2011).

\section{Acknowledgments}

The PERDOVE study was supported by a grant from the Associazione Fatebenefratelli for Research (AFAR). It is registered with ClinicalTrials.gov; identifier No. NCT01701765. We thank Fra Marco Fabello for his valuable support in conducting this study. The authors report no competing interests.

\section{References}

Becchi, A., Rucci, P., Placentino, A., Neri, G., de Girolamo, G., 2004. Quality of life in patients with schizophrenia-comparison of self-report and proxy assessments. Social Psychiatry and Psychiatric Epidemiology 39, 397-401. 
Bechdolf, A., Klosterkotter, J., Hambrecht, M., Knost, B., Kuntermann, C., Schiller, S., Pukrop, R., 2003. Determinants of subjective quality of life in post acute patients with schizophrenia. European Archives of Psychiatry and Clinical Neuroscience 253, 228-235.

Bengtsson-Tops, A., Hansson, L., 2001. Quantitative and qualitative aspects of the social network in schizophrenic patients living in the community. Relationship to sociodemographic characteristics and clinical factors and subjective quality of life. International Journal of Social Psychiatry 47, 67-77.

Bollen, K.A., 1996. Structural Equation With Latent Variables. John Wiley, New York

Caron, J., Lecomte, Y., Stip, E., Renaud, S., 2005a. Predictors of quality of life in schizophrenia. Community Mental Health Journal 41, 399-417.

Caron, J., Mercier, C., Diaz, P., Martin, A., 2005b. Socio-demographic and clinical predictors of quality of life in patients with schizophrenia or schizo-affective disorder. Psychiatry Research 137, 203-213.

Caron, J., Tempier, R., Mercier, C., Leouffre, P., 1998. Components of social support and quality of life in severely mentally ill, low income individuals and a general population group. Community Mental Health Journal 34, 459-475.

de Girolamo, G., Candini, V., Buizza, C., Ferrari, C., Boero, M.E., Giobbio, G.M., Goldschmidt, N., Greppo, S., Iozzino, L., Maggi, P., Melegari, A., Pasqualetti, P., Rossi, G., 2013. Is psychiatric residential facility discharge possible and predictable? A multivariate analytical approach applied to a prospective study in Italy. Social Psychiatry and Psychiatric Epidemiology 49, 157-167.

de Girolamo, G., Rucci, P., Scocco, P., Becchi, A., Coppa, F., D'Addario, A., Daru, E., De Leo, D., Galassi, L., Mangelli, L., Marson, C., Neri, G., Soldani, L., 2000. Quality of life assessment: validation of the Italian version of the WHOQOL-Bref. Epidemiology and Psychiatric Sciences 9, 45-55.

Eack, S.M., Newhill, C.E., 2007. Psychiatric symptoms and quality of life in schizophrenia: a meta-analysis. Schizophrenia Bulletin 33, 1225-1237.

Eklund, M., Backstrom, M., 2005. A model of subjective quality of life for outpatients with schizophrenia and other psychoses. Quality of Life Research 14, $1157-1168$.

Fitzgerald, P.B., Williams, C.L., Corteling, N., Filia, S.L., Brewer, K., Adams, A., de Castella, A.R., Rolfe, T., Davey, P., Kulkarni, J., 2001. Subject and observer-rated quality of life in schizophrenia. Acta Psychiatrica Scandinavica 103, 387-392.

Fujimaki, K., Morinobu, S., Yamashita, H., Takahashi, T., Yamawaki, S., 2012. Predictors of quality of life in inpatients with schizophrenia. Psychiatry Research 197, 199-205.

Hancock, G.R., Mueller, R.O. (Eds.), 2006. Structural Equation Modeling: A Second Course. Information Age Publishing, Greenwich, CT

Hansson, L., Bjorkman, T., 2007. Are factors associated with subjective quality of life in people with severe mental illness consistent over time?-a 6-year follow-up study. Quality of Life Research 16, 9-16.

Ho, W.W., Chiu, M.Y., Lo, W.T., Yiu, M.G., 2010. Recovery components as determinants of the health-related quality of life among patients with schizophrenia: structural equation modelling analysis. Australian and New Zealand Journal of Psychiatry 44, 71-84.

Hofer, A., Rettenbacher, M.A., Widschwendter, C.G., Kemmler, G., Hummer, M., Fleischhacker, W.W., 2006. Correlates of subjective and functional outcomes in outpatient clinic attendees with schizophrenia and schizoaffective disorder. European Archives of Psychiatry and Clinical Neuroscience 256, 246-255.

Hsiao, C.Y., Hsieh, M.H., Tseng, C.J., Chien, S.H., Chang, C.C., 2012. Quality of life of individuals with schizophrenia living in the community: relationship to sociodemographic, clinical and psychosocial characteristics. Journal of Clinical Nursing 21, 2367-2376.

Huguelet, P., Mohr, S., Betrisey, C., Borras, L., Gillieron, C., Marie, A.M., Rieben, I. Perroud, N., Brandt, P.Y., 2011. A randomized trial of spiritual assessment of outpatients with schizophrenia: patients' and clinicians' experience. Psychiatric Services 62, 79-86.

Hwang, S.S., Lee, J.Y., Cho, S.J., Lee, D.W., Kim, Y.S., Jung, H.Y., 2009. The model of the relationships among the predictors of quality of life in chronic stage of schizophrenia. Progress in Neuro-Psychopharmacology and Biological Psychiatry $33,1113-1118$.

Iverson, G.L., Brooks, B.L., Haley, G.M., 2009. Interpretation of the RBANS in inpatient psychiatry: clinical normative data and prevalence of low scores for patients with schizophrenia. Applied Neuropsychology 16, 31-41.

Kelly, S., McKenna, H., Parahoo, K., Dusoir, A., 2001. The relationship between involvement in activities and quality of life for people with severe and enduring mental illness. Journal of Psychiatric and Mental Health Nursing 8, 139-146.

Kupek, E., 2006. Beyond logistic regression: structural equations modelling for binary variables and its application to investigating unobserved confounders. BioMed Central Psychiatry 6, 13.

Landolt, K., Rossler, W., Burns, T., Ajdacic-Gross, V., Galderisi, S., Libiger, J., Naber, D. Derks, E.M., Kahn, R.S., Fleischhacker, W.W., 2012. The interrelation of needs and quality of life in first-episode schizophrenia. European Archives of Psychiatry and Clinical Neuroscience 262, 207-216.

Mohr, S., Perroud, N., Gillieron, C., Brandt, P.Y., Rieben, I., Borras, L., Huguelet, P., 2011. Spirituality and religiousness as predictive factors of outcome in schizophrenia and schizo-affective disorders. Psychiatry Research 186, 177-182.

Morosini, P.L., Magliano, L., Brambilla, L., Ugolini, S., Pioli, R., 2000. Development, reliability and acceptability of a new version of the DSM-IV Social and Occupational Functioning Assessment Scale (SOFAS) to assess routine social functioning. Acta Psychiatrica Scandinavica 101, 323-329.

Narvaez, J.M., Twamley, E.W., McKibbin, C.L., Heaton, R.K., Patterson, T.L., 2008. Subjective and objective quality of life in schizophrenia. Schizophrenia Research 98, 201-208.

Nolan, J.A., McEvoy, J.P., Koenig, H.G., Hooten, E.G., Whetten, K., Pieper, C.F., 2012. Religious coping and quality of life among individuals living with schizophrenia. Psychiatric Services 63, 1051-1054.

Norman, R.M., Malla, A.K., McLean, T., Voruganti, L.P., Cortese, L., McIntosh, E., Cheng, S., Rickwood, A., 2000. The relationship of symptoms and level of functioning in schizophrenia to general wellbeing and the quality of life scale. Acta Psychiatrica Scandinavica 102, 303-309.

Paloutzian, R., Ellison, C., 1982. Loneliness, spiritual well-being and the quality of life. In: Peplau, L., Perlman, D. (Eds.), Loneliness: A Sourcebook of Current Theory, Research, and Therapy. Wiley-Interscience, New York, pp. 224-237

Picardi, A., Rucci, P., de Girolamo, G., Santone, G., Borsetti, G., Morosini, P, 2006. The quality of life of the mentally ill living in residential facilities: findings from a national survey in Italy. European Archives of Psychiatry and Neurological Sciences 256, 372-381.

Ponteri, M., Pioli, R., Padovani, A., Tunesi, S., de Girolamo, G., 2007. RBANS Repeatable Battery for the Assessment of Neuropsychological Status. Organizzazioni Speciali, Firenze (Italian version)

Ritsner, M.S., Arbitman, M., Lisker, A., Ponizovsky, A.M., 2012. Ten-year quality of life outcomes among patients with schizophrenia and schizoaffective disorder II. Predictive value of psychosocial factors. Quality of Life Research 21, 1075-1084.

Rosmarin, D.H., Bigda-Peyton, J.S., Öngur, D., Pargament, K.I., Björgvinsson, T., 2013. Religious coping among psychotic patients: relevance to suicidality and treatment outcomes. Psychiatry Research 210, 182-187.

Ruggeri, M., Bisoffi, G., Fontecedro, L., Warner, R., 2001. Subjective and objective dimensions of quality of life in psychiatric patients: a factor analytical approach: the South Verona outcome project 4. British Journal of Psychiatry $178,268-275$.

Ruggeri, M., Dall'Agnola, R., Agostini, C., Bisoffi, G., 1994. Acceptability, sensitivity and content validity of the VECS and VSSS in measuring expectations and satisfaction in psychiatric patients and their relatives. Social Psychiatry and Psychiatric Epidemiology 29, 265-276.

Ruggeri, M., Gater, R., Bisoffi, G., Barbui, C., Tansella, M. 2002. Determinants of subjective quality of life in patients attending community-based mental health services. The South-Verona outcome project 5. Acta Psychiatrica Scandinavica $105,131-140$.

Ruggeri, M., Lasalvia, A., Bisoffi, G., Thornicroft, G., Vazquez-Barquero, J.L., Becker, T., Knapp, M., Knudsen, H.C., Schene, A., Tansella, M. EPSILON Study Group, 2003. Satisfaction with mental health services among people with schizophrenia in five European sites: results from the EPSILON study. Schizophrenia Bulletin 29, $229-245$.

Shah, R., Kulhara, P., Grover, S., Kumar, S., Malhotra, R., Tyagi, S., 2011. Contribution of spirituality to quality of life in patients with residual schizophrenia. Psychiatry Research 190, 200-205.

Silverstein, S.M., Bellack, A.S., 2008. A scientific agenda for the concept of recovery as it applies to schizophrenia. Clinical Psychology Review 28, 1108-1124.

Slade, M., Leese, M., Ruggeri, M., Kuipers, E., Tansella, M., Thornicroft, G., 2004. Does meeting needs improve quality of life? Psychotherapy and Psychosomatics 73, 183-189.

Ventura, J., Green, M.F., Shaner, A., Liberman, R., 1993. Training and quality assurance with the brief psychiatric rating scale: the drift busters. International Journal of Methods in Psychiatric Research 3, 221-244.

Wilson-d'Almeida, K., Karrow, A., Bralet, M.C., Bazin, N., Hardy-Bayle, M.C., Falissard, B., 2013. In patients with schizophrenia, symptoms improvement can be uncorrelated with quality of life improvement. European Psychiatry 28, 185-189.

Wing, J.K., Beevor, A.S., Curtis, R.H., Park, S.B., Hadden, S., Burns, A., 1998. Health of the Nation Outcome Scales (HoNOS). Research and development. British Journal of Psychiatry 172, 11-18.

Zissi, A., Barry, M.M., Cochrane, R., 1998. A mediational model of quality of life for individuals with severe mental health problems. Psychological Medicine 28, 1221-1230. 